Pau Bori*

https://doi.org/10.18485/analiff.2020.32.1.14

Departamento de Estudios Ibéricos

378.147:811.134.1

Facultad de Filología

Universidad de Belgrado

Originalni naučni rad

Primljen: 17.03.2020.

Prihvaćen: 15.06.2020.

\title{
LA ENSEÑANZA DEL CATALÁN EN EL MUNDO Y LA CATALANÍSTICA INTERNACIONAL
}

El presente artículo realiza un recorrido por la historia de la enseñanza del catalán —y de los estudios catalanes en general — en los países de fuera del dominio lingüístico catalán. Empieza con los orígenes de la catalanística internacional para relatar, a continuación, la introducción de los estudios catalanes en las primeras universidades extranjeras a principios del siglo XX y su posterior expansión a lo largo del siglo pasado, especialmentea partir del final de la dictadura franquista. Más adelante, se muestra como la creación en 2002 del InstitutRamonLlull amplió aún más el número de centros en el mundo que ofrecen estudios catalanes y se cartografía el estado actual de esta disciplina a nivel global. El artículo, además, señala la situación paradójica de la lengua catalana, queen el interior de sus fronteras lingüísticassufre en unas circunstancias anómalas, mientras que fuera de su dominio lingüístico los estudios catalanes gozan deuna notable vitalidad.

Palabras claves: enseñanza de lenguas; catalán como lengua extranjera; estudios catalanes;catalanística; InstitutRamonLlull

\section{Introducción}

A pesar de existir varias investigaciones dedicadasa la historia de la enseñanza del catalán en un país extranjero concreto o en una zona geográfica determinada, no tenemos constancia de ningún estudio reciente que presente un panorama general de la evolución de los estudios catalanes en todo el mundo. La única obra que se ocupó de ello, Manual de catalanística (Bover, 1993), se publicó hace ya hace más de cinco lustros. El propósito de este artículo es complementar y actualizar las aportaciones de ese libro con un recorrido por la historia de la enseñanza de la lengua catalana - y de los estudios catalanes en general - fuera del dominio lingüístico catalán hasta llegar al estado de esta disciplina en nuestros días.

* pau.bori.sanz@fil.bg.ac.rs 
La situación de la lengua catalana es francamente insólita. En el interior de sus fronteras lingüísticas no goza de oficialidad en todos sus territorios: es la única lengua oficial en Andorra y cooficial (junto con el castellano) en las comunidades autónomas de Cataluña, las Islas Baleares y Valencia (donde el catalán se denomina valenciano), pero no lo es en el sur de Francia,la ciudad italiana del Alguero (en Cerdeña) o en la zona másoriental de Aragón (denominada Franja de Ponent). El catalán tampoco es una lengua oficial en las instituciones de la Unión Europea. Además, muchas de las personas que viven en determinadas zonas de estos territorios desconocen el catalán o prescinden de él en sus vidas diarias. Sin embargo, fuera del dominio lingüístico catalán, ha habido (y hay) muchas personas que deciden estudiar esta lengua. De hecho, según los datos que expondremos a continuación, la presencia de los estudios catalanes en el mundo es comparable (e incluso superior) al de los estudios de lenguas con un número de hablantes parecido (Villatoro, 2012: 57; Puiggené, 2014: 2)y que, a diferencia del catalán, disponen de un estado propio ${ }^{1}$, como el finlandés, el noruego, el danés, el checo, o el serbio.

\section{Los orígenes de la catalanística internacional}

El filólogo e historiador Josep Massot i Muntaner, en su estudio sobre la catalanística en los siglos XIX y XX, propone la siguiente definición de este concepto:

Catalanística es el nombre dado, en general, alestudio de la cultura de los Países Catalanes: lengua, literatura, historia, arte, música, etnografía, etc. Más concretamente, el nombre de 'catalanística' se aplica al conjunto de aportaciones de la cultura catalana realizadas por investigadores no catalanes(1996: 283) ${ }^{2}$.

Según AugustBover (2012), uno de los máximos expertos en catalanística internacional, las personas que se dedican a este campo de estudio se deberían denominar'catalanistas', un término preferible al de

$1 \quad$ El catalán no es la lengua oficial de ningún estado, a excepción del microestado de Andorra, en los Pirineos.

2 Todas las citas en catalán han sido traducidas al español por el autor de este artículo. 
'catalanófilos', muy utilizado durante la dictadura de Franco, pero que hoy día tiene unas connotaciones de aficionado que no se corresponden a los profesionales de los estudios catalanes.

Para buscar los orígenes de la catalanística internacional, nos deberíamos remontar al menosal vasto movimiento luliano europeo medieval, que continuó en el Renacimiento y el Barroco con figuras tan importantes como la del controvertido filósofo italiano Giordano Bruno o el pensador alemán Gottfried Leibniz (Bonner, 1988). Como es sabido, el interés erudito por la obra y la figura deRamonLlull se ha mantenido vivo hasta nuestros días con numerosos estudios sobre el pensamiento luliano, tanto en Europa como en América,recogidos en su mayoría en elboletín bibliográfico de la revista StudiaLulliana.

No obstante,será en la segunda mitad del siglo XIX cuando podemos hablar de una auténtica difusión de la catalanística a nivel internacional (Bover, 2012), con figuras como los francesesAlfred Morel-Fatio y Francesc Cambouliu (originario de la Cataluña francesa), los alemanes Adolf HelfferichyOtto Denk o los españoles José Amador de los Ríos y su discípulo Marcelino Menéndez y Pelayo, entre otros.

La celebración del Primer Congreso Internacional de la Lengua Catalana en Barcelona el 1906, impulsado por el lingüista i folclorista mallorquín Antoni M. Alcover, representará, entre otros hitos, la confirmación del interés definitivo por la catalanística a nivel internacional (Bover, 1993). Entre los lingüistas y eruditos extranjeros que participaron o se adhirieron al evento, encontramos algunos de los grandes romanistas no catalanes del momento, como los ya mencionados Morel-Fatioy Menéndez y Pelayo, o el alemán Jean-Joseph Saraïhandy(Segarra, 2006).

A continuación, apareceránlas investigacionesdel lingüista francés Raymond Fouché-Delbosc, amigo de PompeuFabra (el normativizador de la lengua catalana), que abrirán las páginas de la RevueHispaniqueainvestigaciones sobre literatura catalana,las contribuciones italianas con estudiosos como Mario Casella, Arturo Farinelli, Enzio Levi o Bernardo Sanvisenti,la publicación el 1925 en Heidelberg de la polémica obra Das Katalanische del romanista suizo Wilhelm Meyer-Lübke sobre el origen y la filiación románica del catalán, o las aportaciones del catalanista inglés Edgar Allison Peers, fundador del Bulletin of HispanicStudies (Bover, 1993). 


\section{Primeras universidades}

\subsection{Europa}

En las primeras décadas del siglo XX el estudio de la lengua y cultura catalanas se implanta en Alemania, gracias a BenhardSchädel, lingüista colaborador de Antoni M. Alcover yprofesor primero en la Universidad de Halle y, a partir de 1911, en la de Hamburgo. Después de unas breves estancias en Mallorca, Schädel imparte un primer curso de catalán en Halle el otoño de 1904, curso que repite el año siguiente (Eberenz-Greoles, 1990). De la mano de Schädel, llega a Alemania el especialista en literatura catalana medieval Jordi Rubiói Balaguer, que impartirá clases de catalán durante tres semestres en la Universidad de Hamburgo, entre 1911 y 1913 (Eberenz-Greoles, 1990). Después de la Primera Guerra Mundial, el crítico e historiador de la literatura Manuel de Montoliuserá el encargado de los cursos de catalán en la Universidad de Hamburgo (Janué, 2012).

En Francia, a partir de 1909, el erudito de la Cataluña francesa Joan Amade organiza cursos de lengua y literatura catalanas en la Universidad de Montpellier (Bernardo, 1975). También tenemos noticia que el escolapio húngaro AlbinKorösi - lector de español en la Universidad de Budapest entre 1912 y 1936 - ofrece cursos de catalán a alguno de sus alumnos de forma no institucionalizada (Faluba, 2007). En la Universidad Carolina de Praga, donde ya a principios del siglo XX el poeta y traductor checo JaroslavVrchlický había impartido algunos cursos no curriculares de literatura catalana (Bauçà, 2008), en los años treinta y cuarenta del siglo pasado el lingüista y traductor checo Rudolf JanSlabyimparte clases de lengua catalana dentro de la Facultad de Filosofía y Letras (Schejbal, 2007).

En la Gran Bretaña, los estudios catalanes empiezan en los años veinte del siglo pasado con los profesores IgnasiGonzàlez-Llubera en la Queen'sUniversity de Belfast y el ya mencionado Edgar Allison Peers en la Universidad de Liverpool. De esta forma, Gonzàlez-Llubera - hispanista catalán residente en Belfast - y Allison Peers — romanista y pedagogo británico que tradujo RamonLlull al inglés - abrieron las puertas de las universidades británicas a los estudios de literatura y lingüística catalanas (Bover, 1989; MassotiMuntaner, 1996).

Después de la Segunda Guerra Mundial, se retoman los estudios catalanes en las universidades de las Islas Británicas, básicamente por dos motivos. Por un lado, la guerra civil española había originado un mayor 
interés entre los británicos por España y, en particular, por Cataluña (Edo de Grigg, 1992). Por otro lado, varios intelectuales catalanes se exiliaron a Inglaterra, entre los cuales destaca Josep M. Batista i Roca que, desde la Universidad de Cambridge, contribuyó decisivamente a la formación de catalanistas británicos. Arthur Terry, uno de sus discípulos, empezó a impartir clases de lengua y literatura catalanas el 1950 en la Universidad de Queen's, en Belfast, donde se convirtió en catedrático el 1962, hasta que el 1973 ingresó en Essex.

El 1954 Josep M. Batista i Roca, junto con otros catalanistas británicos, funda laAnglo-CatalanSociety, la decana de las asociaciones de la catalanística internacional, que trabajó para aumentar el número de universidades británicas que ofrecían cursos de lengua y cultura catalanas. Progresivamente, fueron apareciendo nuevos catalanistas británicos que, desde sus cátedras de hispánicas, introdujeron los estudios catalanes, como por ejemplo Alan Yates en la Universidad de Sheffield o, más adelante, Max Wheeler en las Universidades de Liverpool y Sussex. En los años cincuenta y sesenta, también llegaron una serie de lectores de español de origen catalán (Montserrat Roig, Max Chaner, Albert Hauf o Toni Turull) que fueron introduciendo los estudios catalanes en sus universidades británicas, siempre de una forma extraoficial, pero en algunas ocasiones abrieron el caminopara que más adelante el catalán se incorporaraenlos planes de estudios (Carbonell, 1998).

A partir de los años sesenta, el interés por los estudios catalanes va aumentando progresivamente en diferentes universidades extranjeras:

Poco a poco, y a menudo a merced de la insistencia de profesores catalanes exiliados, los estudios de lengua y literatura catalanas consiguieron hacerse un hueco en los planes de estudios de algunas universidades europeas y norteamericanas, destacando su importancia en los programas de estudios hispánicos o románicos o bien, incluso, a través de la creación de asignaturas específicas (Bover, 1993: 21-22).

En Francia, por ejemplo, donde la Universidad de Tolosa fue la primera a introducir cursos regulares de catalán para francófonos ya el 1949, encontramos que a lo largo de la década de los sesenta también se inician estudios catalanes en las universidades de Marsella, Burdeos, Limoges, Perpiñán, Poitiers, Rennes, o Estrasburgo (Forasté, 1982). 
El 1973, en la Universidad de Cambridge, estudiosos catalanistas, tanto extranjeros como catalanes, fundaron la Associació de Llengua $i$ Literatura Catalanes (AILLC), entidad que cada tres años celebra un congreso internacional sobre estudios catalanes e impulsa la revista Estudis de Llengua i Literatura Catalanes, donde se publicaninvestigaciones de catalanistas extranjeros.

El fin de la dictadura franquista en 1975 y la posterior recuperación de las instituciones catalanas ayudaron de una forma decisiva a la expansión de los estudios catalanes en el extranjero. A finales de los años setenta, según señala Roca-Pons (1979), ya se impartían estudios catalanes en varias universidades francesas (Ais de Provenza, Burdeos, Estrasburgo, Montpellier, París, Rennes, Tolosa, etc.), británicas (Aberdeen, Belfast, Bristol, Cambridge, Cardiff, Durham, Glasgow, Liverpool, Londres, Notthingam, St. Andrews de Escocia, Sheffield, etc.), alemanas ( Berlín, Erlangen-Núremberg, Friburgo, Maguncia, Heidelberg, Múnich, Münster, Rastisbona, etc.), y también en la Universidad de Ámsterdam, la de Estocolmo,la de Basilea con el romanista valenciano Germà Colon, o en la de Cagliari (Cerdeña) de la mano del filólogo y político catalán Jordi Carbonell.

En la Europa oriental entonces comunista, a pesar de las escasas relaciones con la España franquista, varias universidades empezaron también a ofrecer cursos de catalán incluso antes de la muerte de Franco. El 1956 se inician unos cursos específicos de lengua y cultura catalanas en la Universidad de Bucarest (Cerdà, 1982); Diana Foix —hija de exiliados catalanes - comenzó el 1961 a impartir clases de catalán en la Universidad de Carolina de Praga (Schejbal, 2007) y el 1971 se inician en la Universidad de Budapest de la mano del catalanista húngaro KálmánFaluba (Faluba, 2007), mientras que en la antigua Unión Soviética la universidad Lomonóssov de Moscú instauró clases de lengua catalana el 1977 (Abramova, 2007).

Ese mismo año 1977, la Universidad de la Sorbona pone en funcionamiento en París su Centro de Estudios Catalanes, y el 1978, en Italia, profesores universitarios de filología, lingüística, literatura o historia del arte, que ya hacía tiempo que se dedicaban a los estudios catalanes, constituyen la Associazione Italiana di StudiCatalani(AISC), con el objetivo de dar un mayor protagonismo a la cultura catalana en los currículums universitarios y en las investigaciones académicas italianas. 


\subsection{Norteamérica}

Al otro lado delAtlántico, el 1978se constituía en la Universidad de Illinois la North American CatalanSociety (NACS), que organiza congresos internacionales de catalanística y, además, publica la revista TheCatalanReview: International Journal of Catalan Culture. Aunque la tradición de la catalanística en Norteamérica no es tan antigua como en Europa, se deben mencionar los estudios de la profesora de la Universidad de California, Josephine de Boer, que a partir de los años treinta ya se interesó por la literatura catalana moderna y, sobre todo, la tarea a partir de los años cuarenta del destacado lingüista catalán Joan Coromines, desde la Universidad de Chicago, para despertar el interés por el catalán entre los círculos universitarios de los Estados Unidos y Canadá (Bover, 1989). El trabajo de Coromines y de Boer, junto con el de otros profesores norteamericanos y catalanes exiliados, permitió la creación el 1958 de una sección catalano-provenzal en los congresos anuales de la ModernLanguageAssociation (MLA), lo que se puede considerar como el primer paso hacia la posterior constitución de la NACS. Barralsintetiza de la siguiente manera cuál era la situación de los estudios de catalán en Norteamérica a principios de los setenta:

La historia de la enseñanza del catalán en las universidades americanas es bastante reciente, pero impresiona por la rapidez con que esta enseñanza se ha difundido. Sin que hubiera prácticamente nada antes de 1965, ahora son más de dieciocho las universidades que enseñan el catalán (1971: 147).

\subsection{Países de lengua española}

En el centro y el sur de América, el interés por los estudios catalanes fue posterior y de una menor magnitud que en el norte del continente, a pesar de que algunos países como México, Argentina, Cuba o Chile habían acogido numerosos intelectuales catalanes después de la derrota de 1939. Ni siquiera el eminente lingüistaJoan Corominesconsiguió sentar las bases para el desarrollo de la catalanística en América Latina durante su etapa argentina en la Universidad de Cuyo,en Mendoza, en los años posteriores a la guerra civil.Según Malkiel (1968), a finales de la década de los sesenta no existen estudios catalanes en ninguna universidad de América del Sur o 
Centroamérica. Será solo a partir del1982 cuando, en Argentina,el Centro Catalán de Rosario (creado por inmigrantes catalanes y sus descendientes) empieza a ofrecer clases de catalán de una forma regular, primero para estudiantes catalanohablantes y, a partir de 1986, también para no catalanohablantes (Miyara y Flores, 1991). Pero tendremos que esperar aúnhasta el 1991 para que aparezca el primer curso universitario de catalán en la América Latina, en la Universidad Nacional de Rosario.

En los territorios españoles defuera del dominio lingüístico catalán, los estudios catalanes tampoco tuvieron tradicionalmente mucho arraigo, como consecuencia, en gran parte, de las cuatro décadas de la dictadura franquista $^{3}$. A principio de la década de los ochenta, Frago(1982: 61) considera que su situaciónes "harto precaria, igual que sucede con otras lenguas románicas, como es el caso del occitano o, para no salir de los límites españoles, del gallego fuera de su propio marco territorial”. En aquel momento, las universidades de Málaga, Granada, Córdoba y las universidades Autónoma y Complutense de Madrid ofrecían clases de lengua o literatura catalanas dentro de sus planes curriculares. Entre las universidades españolas (fuera del dominio lingüístico) pioneras en los estudios catalanes, cabe destacar la de Granada que ya desde 1963 ofrece asignaturas de filología catalana dentro de sus planes de estudios (Sánchez, 1992) y la Complutense de Madrid que los ofrece desde el curso académico 1969-70 (Ribera, 2007).

\section{Enseñanza del catalán a finales del siglo $X X$}

El creciente interés internacional por los estudios catalanes después de la muerte de Franco, especialmente en Europa y Norteamérica, y la consiguiente demanda de profesores para los lectorados de catalán, creados en universidades de estas zonas, determinaron que el 1989 la Generalitat de Cataluña fundara la Comisión para la promoción de la enseñanza del catalán en universidades de fuera del ámbito territorial de Cataluña, más conocida como la Comisión de Lectorados. Como precedente inmediato de esta institución, se debe señalar que el curso 1987-1988 la Generalitat ya había constituido una primera red de lectorados junto con ocho universidades

3 La dicatura de Franco prohibió el uso público de todas las lenguas habladas en España distintas al castellano. 
de tres países extranjeros: Alemania, Bélgica y la Unión Soviética. Las principales funciones de la Comisión de Lectorados fueron el asesoramiento, las relaciones con las universidades, la selección y formación de docentes, y la elaboración de materiales como elFull Informatiu del Lector(FIL) que recibió el profesorado de catalán en el extranjero desde 1991. De forma progresiva,la Comisión de Lectorados cada vez irá apoyando más universidades de fuera del dominio lingüístico catalán, como podemos observar en la Tabla 1.

Tabla 1. Número de lectorados de catalán con el apoyo de la Comisión de Lectorados por curso académico (1987-2002):

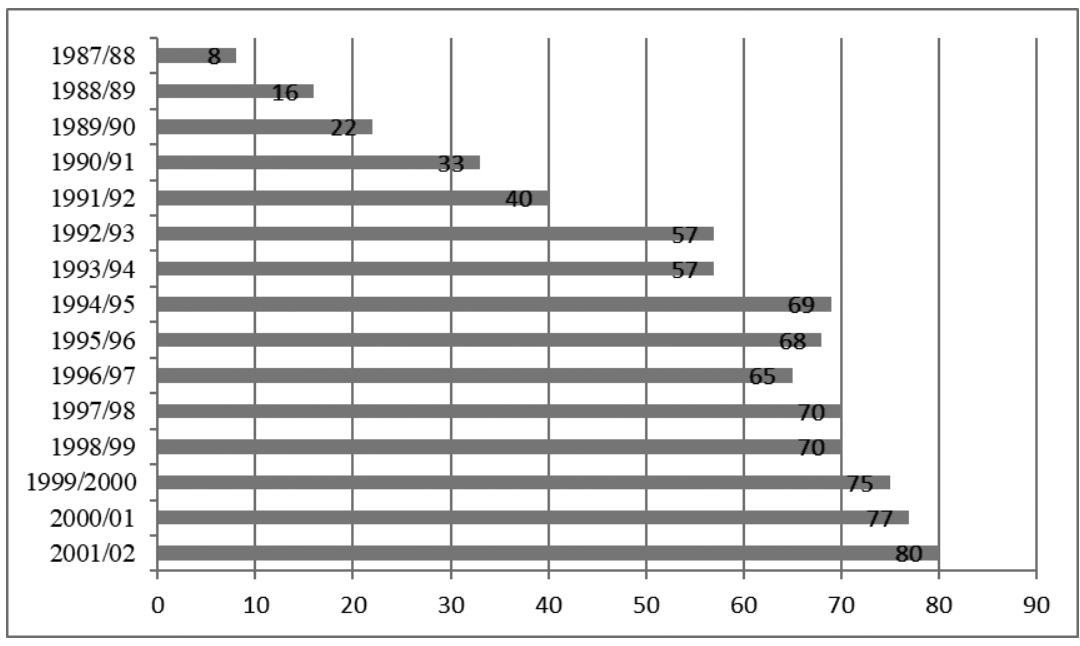

Fuente: Franquesa (2005: 280).

Durante las dos últimas décadas del siglo pasado, con o sin el apoyo de la Comisión de Lectorados, continuamenteson más las universidades y centros del extranjero que ofrecen asignaturas de estudios catalanes. De hecho, en 1989 ya había 93 lugares fuera de los territorios de habla catalana donde se enseñaba catalán, 67 de los cuales eran universidades y 26 casales o institutos de idiomas (Gimeno, 1989). Dos años después, encontramos ya 142 centros fuera del ámbito lingüístico catalán donde se ofrecen cursos de estudios catalanes, 105 de los cuales son universidades: "Por países destacan Alemania con 34 centros, el Reino Unido con 17 centros, Francia con 15 centros y Estados Unidos con 14 centros" (Reniu, 
1993: 435). Además decentros en la Europa occidental y en Norteamérica, hay que destacar también la creación de nuevos lectorados de catalán y la consolidación de los ya existentes en la Europa oriental: en Hungría (Faluba, 2007), Rusia (Abramova, 2007), Polonia (Ysern, 1992; Sawicka, 2007), Rumanía (Llinàs, 2007) y la República checa (Marina, 2007). También en la América Central ydel Sur, a finales del siglo pasado, empezaron a introducirse los estudios catalanes en países como Argentina, Uruguay, México o Cuba. De hecho, alrededor del final del milenio, según Bover (2000), el catalán ya se enseña en los cinco continentes, con dos universidades en Australia, tres en Asia (Seúl, Pekín y Tokyo), y una en África (el catalán se empezó a enseñar en la Universidad de Yaundé del Camerún durante el curso 1993/1994).

Por otro lado, también hay que mencionar las clases de catalán que ofrecen casales catalanes de todo el mundo. Durante el régimen franquista, las clases de catalán que ofrecían estas instituciones iban generalmente dirigidas a catalanohablantes. Más adelante, algunos de estos centros también empezaran a ofrecer cursos específicos para no catalanohablantes adultos, a pesar de que en general de una forma bastante irregular:

Se trata de una enseñanza bastante inestable, porque siempre va ligado a la disponibilidad de una persona mínimamente preparada -no siempre fácil de conseguir- y de un número de personas con suficiente interés y tiempo para asistir a unas clases que normalmente no necesitan para su promoción social y laboral (Bover, 2000: 465).

\section{Siglo XXI: EI InstitutRamonLlull}

A partir de 2002, el InstitutRamonLlull (IRL) cogió el relevo de la Comisión de Lectorados en relación con el apoyo a la enseñanza de la lengua, la literatura y la cultura catalanas en centros de fuera del dominio lingüístico catalán. El IRL nació como un consorcio entre los gobiernos catalán y balear para la promoción exterior conjunta de estudios catalanes en el ámbito académico, la traducción de obras catalanas y la producción cultural catalana en ámbitos como el teatro, el cine, la música o la danza. En la actualidad (año 2020), el IRL está integrado por los gobiernos catalán y balear, y el ayuntamiento de Barcelona, y tiene convenios de colaboración 
con instituciones como la Academia Valenciana de la Lengua o la red de universidades catalanas Xarxa Vives d'Universitats.

El IRL empezó su trayectoria el curso académico 2002-2003 con una red integrada por 85 universidades de 23 países diferentes (Franquesa, 2005). Desde entonces, promueve los estudios de lengua y cultura catalanas en las universidades del exterior y apoya a las universidades, el profesorado y los estudiantes a través de varios programas y líneas de ayuda (Puiggené, 2014). Como podemos ver en la Tabla 2, la red de universidades con apoyo del IRL fue aumentando de una forma progresivahasta llegar a un máximo de 126 universidades en el curso 2007-2008.Al cabo de unos años (en el curso 2013-14), durante un periodo de máxima austeridad presupuestaria del gobierno de la Generalitat de Cataluña, se redujeron significativamente las subvenciones del IRL a universidades de fuera del dominio lingüístico catalán y, desde entonces, el número de universidadesconayudas delIRL se ha mantenido estable, entre las 86 y 88 .

Tabla 2. Número universidades con ayuda del IRL por continentes y cursos académicos (2003-2019).

\begin{tabular}{|c|c|c|c|c|c|c|}
\hline Curso & Europa & América & Asia & Oceanía & África & TOTAL \\
\hline $2003 / 04$ & 76 & 13 & 1 & 1 & 2 & 93 \\
\hline $2004 / 05$ & 78 & 13 & 1 & 1 & 2 & 95 \\
\hline $2005 / 06$ & 81 & 14 & 1 & 1 & 1 & 98 \\
\hline $2006 / 07$ & 87 & 17 & 1 & 1 & 1 & 107 \\
\hline $2007 / 08$ & 98 & 24 & 2 & 1 & 1 & 126 \\
\hline $2008 / 09$ & 96 & 21 & 3 & 1 & 1 & 122 \\
\hline $2009 / 10$ & 96 & 23 & 4 & 1 & 1 & 125 \\
\hline $2010 / 11$ & 93 & 24 & 5 & 0 & 1 & 123 \\
\hline $2011 / 12$ & 87 & 24 & 3 & 0 & 0 & 114 \\
\hline $2012 / 13$ & 87 & 23 & 3 & 1 & 0 & 114 \\
\hline $2013 / 14$ & 67 & 18 & 2 & 1 & 0 & 88 \\
\hline $2014 / 15$ & 66 & 16 & 3 & 1 & 0 & 88 \\
\hline $2015 / 16$ & 66 & 17 & 4 & 1 & 0 & 88 \\
\hline $2016 / 17$ & 66 & 17 & 4 & 0 & 0 & 87 \\
\hline $2017 / 18$ & 66 & 16 & 4 & 0 & 0 & 86 \\
\hline $2018 / 19$ & 67 & 16 & 4 & 0 & 0 & 87 \\
\hline
\end{tabular}

Fuente: InstitutRamonLlull (2019: 60) 
En el curso 2003-2004 hubo alrededor de 6.000 inscripciones a cursos de estudios catalanes en las 93 universidades que contaron con una subvención del IRL;la gran mayoría de estudiantes seguían asignaturas de lengua catalana, especialmente de niveles iniciales (Franquesa, 2007). Según los últimos datos disponibles ${ }^{4}$ (InstitutRamonLlull, 2019: 58), en el curso 2017-2018, hubo 6194 inscripcionesa cursos de estudios catalanes por parte de un total de 3670 estudiantes en las 86 universidades que recibieron una subvención del IRL. Las asignaturas de lengua catalana son las que tuvieron un mayor nombre de matriculaciones $(64,7 \%)$, sobre todo la de nivel Básico y Elemental, mientras que un 35,3 7\% de los estudiantes se inscribieron a asignaturas de literatura, cultura, lingüística y traducción. Por países, el mayor número de estudiantes pertenecen a universidades de Francia, Gran Bretaña y Alemania. También es relevante destacar el gran número de inscritos (más de 150)en cursos de estudios catalanes en universidades de la República checa, Méjico, Rumanía o Serbia (InsitutRamonLlull 2019: 58). Por otro lado, el IRL también fomenta los estudios avanzados y la investigación en catalanística en diversos centros de estudios de catalanística y cátedras de profesores invitados existentes en varias universidades extranjeras: la Sorbona de París, Queen Mary de Londres, de Chicago, de Stanford, City University de Nueva York, de la Havana, de Leizpig, y Adam Mickiewicz de Poznan (InstitutRamonLlull, 2019: 62-64).

Además de las universidades que reciben financiamientodel IRL, hay otros centros universitarios de fuera del dominio lingüístico catalán donde también se impartenestudios catalanes, como el lectorado de catalán en la universidad Carolina de Praga que tiene el apoyo del gobierno de Andorra o los lectorados de valenciano de algunas universidades valencianas. El curso 2003-2004, por ejemplo, había 34 universidades de fuera del dominio lingüístico catalán que ofrecían asignaturas de lengua o literatura catalanas sin el apoyo del IRL, con un total de 1.200 alumnos (Franquesa, 2007). En el curso 2019-2020, según los datos que recoge la página web del IRL (InstitutRamonLlull, 2020),habría más de 150 universidades de fuera del dominio lingüístico catalán que imparten

$4 \quad$ La última memoria del IRL disponible en el momento de redactar este artículo (enero de 2020) corresponde al año 2018. Las memorias del IRL se pueden consultar en el siguiente enlace: https://www.llull.cat/catala/quisom/memories.cfm (31/01/2020). 
cursos de estudios catalanes (con o sin una subvención del IRL), como podemos ver en la Tabla 3:

Tabla 3. Número de universidades con estudios catalanes fuera del dominio lingüístico catalán durante el curso académico 2019-2020 por zonas geográficas:

\begin{tabular}{|c|c|c|c|c|}
\hline Europa & Norteamérica & Suramérica & Asia & TOTAL \\
\hline 111 & 36 & 6 & 6 & 159 \\
\hline
\end{tabular}

Fuente: InstitutRamonLull, 2020.

La expansión de los estudios catalanes en universidades de todo el mundo en las últimas décadas ha supuesto que la lengua $-\mathrm{y}$ la culturacatalana ya no se enseña solo dentro de los departamentos de hispánicas o románicas, sino que también empiezan a aparecer cursos de catalán en estudios no vinculados a la filología o la traducción (Casacuberta y Lomena, 2012).

Aparte de las universidades, también hay otros centros extranjeros que ofrecen (o han ofrecido) en los últimos años cursos de catalán para no catalanohablantes adultos, como algunos Institutos Cervantes (Moscú, Bucarest, Londres, Berlín, Múnich,Burdeos, Belgrado, etc.) o determinados casales catalanes y baleares (Madrid, Toulouse, Marsella, Luxemburgo, Rosario, México, Buenos aires, Mar del Plata, Santa fe, México, etc.), y otros institutos o academias de lenguas.

Por otro lado, relacionado con la enseñanza del catalán en el exterior, el IRL organiza cada año pruebas para la evaluación y la certificación de conocimientos de catalán como lengua extranjera fuera del dominio lingüístico. Los certificados del IRL se estructuran en los mismos cinco niveles que los de la Dirección General de Política Lingüística, de acuerdo con el Marco Europeo Común de Referencia para las lenguas: Básico (A2), Elemental (B1), Intermedio (B2), Suficiencia (C1) y Superior (C2). En2018 las pruebas se administraron en 72 localidades de 30 países de todo el mundo. Se inscribieron un total de 1189 personas, 1079 de las cuales se presentaron al examen (InstitutRamonLlull, 2019: 65): 289 a nivel Básico (A2), 268 a Elemental (B1), 211 a Intermedio (B2), 241 a Suficiencia (C1) y 70 a Superior (C2). Un $75,90 \%$ de los presentados aprobaron la prueba. Los diplomas de lengua catalana del IRL son los herederos de los antiguos certificados internacionales organizados por la Dirección General 
de Política Lingüística de la Generalitat de Cataluña, que se convocaron por primera vez el 1990 en cuatro ciudades europeas con un total de 126 inscritos (Reniu, 1993).

El IRL colabora además con diferentes asociaciones de catalanística. Amén de las ya mencionadas Anglo-CatalanSociety, Associació Internacional de Llengua $i$ Literatura Catalanes, Associazione Italiana di StudiCatalaniyNorth-American CatalanSociety, también existen la asociación germano-catalanaDeutscherKatalanistenverbands, fundada el 1983e impulsora de la revista académica ZeitschriftfürKatalanistik / Revista d'EstudisCatalans(Stegmann, 2007), la AssociationFrançaise des Catalanistes,creada el 2000, y la Asociación de Catalanistas de AméricaLatina, constituidael2012. Todasestasasociacionesestánintegradas en la Federación Internacional de Asociaciones de Catalanística(FIAC), fundada el 2006, de la que también forma parte la Societat Catalana de Llengua i Literatura, sociedad filial del Institutd'EstudisCatalans. En este contexto, debe mencionarse también la tarea delInstitut de Projecció de la Cultura Catalana (IPECC), una entidad sin ánimo de lucro fundada el 1979 que tiene como objetivos promocionar, dentro y fuera del dominio lingüístico catalán, la cultura y la lengua catalanas, fomentar las relaciones entre casales catalanes y asociaciones catalanistas del exterior, y dar a conocer hechos históricos trascendentales para la historia de Cataluña. Cada año otorga los premios Batista i Roca a personas que se han distinguido en la difusión de la cultura catalana fuera de los territorios de habla catalana.

\section{Conclusiones}

A pesar de que los inicios del interés erudito por la lengua y la literatura catalanas a nivel internacional se remontan yaal Medievo, es a partir de las primeras décadas del siglo XX cuando los estudios catalanes se empiezan a introducir en universidades extranjeras. A lo largo del siglo pasado, hay cada vez más universidades que ofrecen cursos de estudios catalanes, pero la expansión de esta disciplina llegará sobre todo después del final de la dictadura franquista, con la instauración el 1989 de la Comisión de Lectorados del gobierno catalán y, especialmente, a partir del 2002, con la creación del IRL.

En el momento de redacción de este artículo (enero de 2020), hay más de 150 universidades de fuera del dominio lingüístico catalán que 
imparten estudios catalanes, una cifra similar (y, en muchos casos, superior) al de los estudios de otras lenguas europeas con un número de hablantes parecido. El desarrollo de una red de universidades con estudios catalanes ha sido posible principalmente gracias al apoyo institucional catalán, que en estas dos últimas décadas gestiona primordialmente el IRL. También han contribuido decisivamente al desarrollo de la enseñanza del catalán en el mundolas asociacionesinternacionales de catalanística e iniciativas de decenas de catalanistas extranjeros (y catalanesafincados en el extranjero) y de determinadas universidades.

Toda esta situación conduce a una coyuntura un tanto paradójicapara la lengua catalana. Dentro de sus fronteras lingüísticas, el catalán vive en unas circunstancias anómalas: división administrativa, oficialidad incompleta, conocimiento y uso escasos en determinadas zonas, numerosas interferencias lingüísticas ocasionadas por el contacto con el castellano, etc. En cambio, fuera de su dominio lingüístico, los estudios catalanes gozan hoy en día de una vitalidad notable, con centenares de asignaturas y miles de estudiantes en todo el mundo.

\section{BIBLIOGRAFÍA}

Abramova, M.A. (2007). La catalanística a Rússia. Jornades de Catalanística a Praga (pp. 67-71). Andorra: Biblioteca Andorrana Internacional.

Barral, X. (1971). L'ensenyament del català a Europa i Amèrica del Nord. Barcelona: GràfiquesRafelSalvà.

Bauçà i Sastre, A. (2008). Un Model de projecció internacional d'Andorra i la sevallengua oficial: el lectorat de català de la universitat Carolina de Praga (descripció i característiques: període 1999-2005). Treballs de sociolingüistica catalana, 19, 71-99.

Bernardo, D. J. (1975). Appareiléducatif et langueautochtone: le cas du catalan. Languefrançaise, 25, 37-61.

Bonner, A. (1988). RamonLlull. Catalònia, 11, 8-9.

Bover, A. (1989). Catalanstudies in English speakingcountries. Bells: Barcelona English language and literaturestudies, 2, 47-51

Bover, A. (1993). Manual de catalanistica.Barcelona: PAMSA i Diputació de Tarragona. 
Bover, A. (2000). Sobre l'estat actual de l'ensenyament del català al món. Actes de l'Onzècol•loqui Internacional de Llengua i Cultura catalanes. Palma, 1997. Volum III (pp. 465-474). Barcelona: PAMSA.

Bover, A (2012). La catalanística internacional en el siglo XXI. En:Presencia catalana en México y el resto de América Latina.Seminario celebrado en Guadalajara, México (29-31 de agosto de 2012).

Carbonell, A. (1998). L'ensenyament del català a la Gran Bretanya.Escola catalana, 350,36-38.

Casacuberta, M., yLomena, M. (2012). Quannormalitat rima ambdiversitat. En: 23è Col·loqui Germano-Català. Congreso celebrado en Berlín, Alemania (27-30 de setiembre de 2012). Disponible en: https://halshs.archivesouvertes.fr/halshs-00786000 (31/01/2020).

Cerdà, R. (1982). El català a la República Socialista de Romania. Estudis de llengua i literatura catalanes, V(pp. 195-197). Barcelona: PAMSA.

Eberenz-Greoles, C. (1990). BernhardSchädel i elsPaïsosCatalans. ZeitschriftfürKatalanistik,3, 137-166.

Edo de Grigg, G. (1992). La situació de l'ensenyament del català a la Gran Bretanya. En: Ponències, comunicacions $i$ conclusions. Segonsimposi sobre l'ensenyament del català a no catalano-parlant. Vic. 4, 5 i 6 setembre 1991 (pp. 237-240). Vic: Eumo.

Faluba, K. (2007). Passat i present de la catalanísticahongaresa. Jornades de Catalanística a Praga (pp.118-123). Andorra: Biblioteca Andorrana Internacional.

Forasté, M. (1982). L'ensenyament del català a les universitats de l'EstatFrancès. Actes del $1 r$ Symposium sobre l'ensenyament del català a no catalanoparlants. Vic, 8/10 d'abril de 1981 (pp. 282-294). Vic: Eumo.

Frago, J.A. (1982). Los estudios catalanes en los países de lengua española. Estudis de llengua i literatura catalanes, V(pp.55-67). Barcelona: PAMSA.

Franquesa, E. (2005). La llengua catalana mésenllà del seuàmbit natural d'ús: Activitats de l'Àrea de Llengua de l'InstitutRamonLlull (2002-2004). Estudisromànics, 27,277-287.

Franquesa, E. (2007). El català, una opciód'estudifora del dominilingüístic. Jornades de Catalanística a Praga (pp.124-132). Andorra: Biblioteca Andorrana Internacional.

Gimeno, M. (1989). L'ensenyament del català en el món. COM ensenyarcatalàalsadults, 19, 34-36.

InstitutRamonLlull (2019). Memòria 2018. Barcelona: InstitutRamonLlull. 
InstitutRamonLlull(2020). Mapa d'estudiscatalans al món. Disponible en: https:// www.llull.cat/catala/aprendre_catala/mapa_llengua.cfm (31/01/2020). Janué, M. (2012). Les relacionsculturalsmútues entre Catalunya i Alemanya en l'etapad'auge del catalanismefins a la fi de la Guerra Civil. En R. Arrabaty A. Gavaldà (Eds.), Projectesnacionals, identitats $i$ relacions Catalunya-Espanya. Homenatge al doctor Pere Anguera, II (pp. 207-220). Catarroja/Barcelona: Afers.

Llinàs, J. (2007). Evolució de la catalanística a un país estranger: El cas de Romania. Jornades de Catalanística a Praga (pp.104-107). Andorra: Biblioteca Andorrana Internacional.

Malkiel, Y. (1968). HispanicPhilology. Currenttrends in linguistics, 4, 158-228.

Marina, J.R. (2007). L'ensenyament del català: Andorra versus la República txeca. Jornades de Catalanistica a Praga (pp.133-136). Andorra: Biblioteca Andorrana Internacional.

Massot i Muntaner, J. M. (1996). Escriptors i eruditscontemporanis (Volum 1). Barcelona: PAMSA.

Miyara, A. J., y Flores, M. S. (1991). L'ensenyament del català a Rosario. COM ensenyarcatalàalsadults, 25, 29-30.

Puiggené, A. (2014). La XarxaUniversitàriad'EstudisCatalans a l'Exterior. Llengua i ús 54, 1-8.

Reniu, M. (1993). El català a l'exterior. Actes del NovèCol-loqui Internacional deLlengua iLiteratura Catalanes. Elx, 1991 (pp. 427-429).Barcelona: PAMSA

Ribera, J.M. (2007). L'ensenyamentuniversitari del català a l'estatespanyol. Jornades de Catalanística a Praga (pp. 178-186). Andorra: Biblioteca Andorrana Internacional.

Roca-Pons, J. (1979).Projecció exterior de la cultura catalana. En: A.P. Mayo, S.W. Baldwin, y J. Martí-Olivella (Eds.), Estudis de llengua, literatura $i$ cultura catalanes, 15 (pp. 41-57). Barcelona: PAMSA.

Sánchez, L. (1992). L'ensenyança del català a la Universitat de Granada. Ponències, comunicacions i conclusions. Segonsimposi sobre l'ensenyament del català a no catalano-parlants. Vic. 4, 5 i 6 setembre 1991 (pp. 289-294). Vic: Eumo.

Sawicka, A. (2007). La catalanística polonesa. Jornades de Catalanística a Praga (pp. 199-208). Andorra: Biblioteca Andorrana Internacional.

Schejbal, J. (2007). La llengua catalana i elstxecs.Jornades de Catalanística a Praga (pp. 209-214). Andorra: Biblioteca Andorrana Internacional. 
Segarra, M.(2006). En el centenari del primer congrés internacional de la llengua catalana a Barcelona, octubre de 1906. EstudisRomànics, 28, 249-265.

Stegmann, T.D. (2007). El català i la cultura catalana a Alemanya.Jornades de Catalanística a Praga (pp. 215-221). Andorra: Biblioteca Andorrana Internacional.

Villatoro, V. (2012). Deuanys de l'InstitutRamonLlull. Experiències i expectatives en la projecció exterior de la llengua i de la cultura catalanes. Llengua i ús, $52,55-59$

Ysern, J.A. (1992). Sobre l'ensenyament del català a Polònia. Ponències, comunicacions $i$ conclusions. Segonsimposi sobre l'ensenyament del català a no catalano-parlants. Vic. 4, 5 i 6 setembre 1991 (pp. 299-304). Vic: Eumo.

\section{Пау Бори}

\section{НАСТАВА КАТАЛОНСКОГ У СВЕТУ И МЕЪУНАРОДНА КАТАЛАНИСТИКА}

\section{Сажетак}

Овај рад представља преглед кроз историју наставе каталонског језика - и каталонских студија уопште - у земљама ван каталонског језичког подручја. Почиње пореклом међународне каталанистике да би у наставку говорио о уводу у студије каталанистике на првим универзитетима у иностранству почетком XX века и њиховој каснијој експанзији, нарочито после краја франкистичке диктатуре. Потом, говори о томе како се стварањем Института Рамон Љуљ 2002. године још више проширио број светских центара који нуде каталонске студије и показује какво је актуелно стање ове дисциплине на светском нивоу. У раду се, поред овога, указује на парадоксалну ситуацију каталонског језика, који унутар својих језичких граница пати од неких аномалних околности, док ван свог лингвистичког подручја, каталонске студије остварују уочљиву виталност.

Кључне речи: настава језика, каталонски као страни језик, каталонске студије, каталанистика, Институт Рамон Љуљ 